\title{
Response to IV immunoglobulin in a case of osmotic demyelination syndrome
}

\author{
Suresh Thirunavukarasu, ${ }_{1}^{1}$ Asthik Biswas, ${ }^{2}$ Farha Furruqh, ${ }^{2}$ Anandavelou Gnanavelan ${ }^{1}$
}

${ }^{1}$ Department of Neurology, Indira Gandhi Government General Hospital and Post Graduate Institute, Puducherry, India

${ }^{2}$ Department of Radiology, Indira Gandhi Government General Hospital and Post Graduate Institute, Puducherry, India

\section{Correspondence to} Dr Suresh Thirunavukarasu, sureshy2001@rediffmail.com

Accepted 3 November 2015

\section{DESCRIPTION}

A 40-year-old man, a chronic alcoholic, presented with left-sided weakness of 2 days duration. Clinical examination revealed stable vitals and left hemiparesis. Routine biochemical examination was normal except for raised liver enzymes. CT of the brain was normal. A working diagnosis of anterior circulation stroke was made and the patient was started on antiplatelets and statins. The following day, he developed difficulty swallowing and quadriparesis. MRI revealed T2/fluid-attenuated inversion recovery hyperintensity with corresponding $\mathrm{T} 1$ hypointensity involving the central pons, crossing the midline and sparing the periphery (figure $1 \mathrm{~A}-\mathrm{C}$ ). Diffusion-weighted imaging (DWI) showed restricted diffusion (figure 1D). MR angiography was normal (figure 2).

A diagnosis of osmotic demyelination syndrome was made based on this imaging appearance. Serum electrolytes were normal. Consequently, the patient developed respiratory paralysis and was intubated and ventilated. His sensorium and eye movements (both horizontal and vertical) were preserved. Bifacial palsy was noted. He became completely

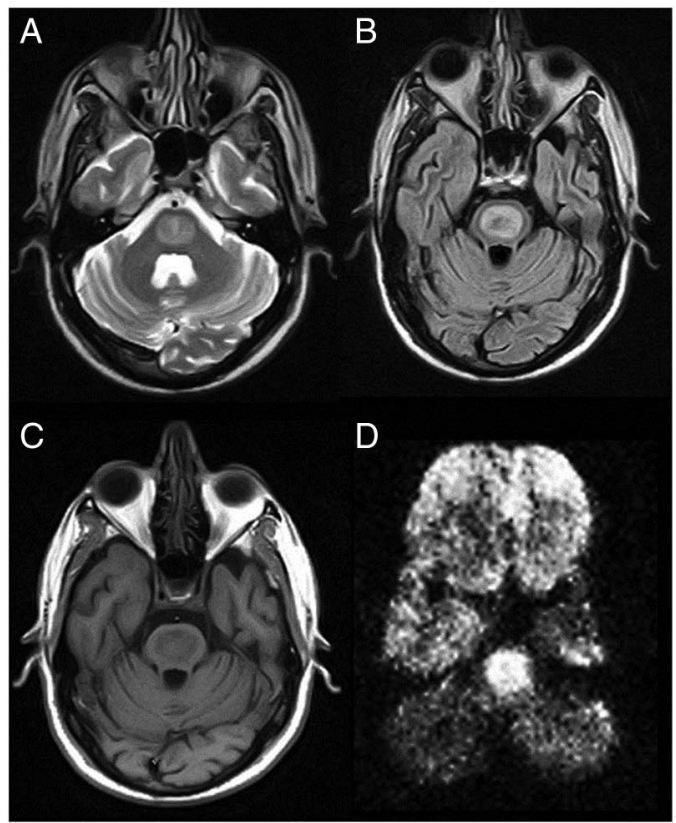

Figure 1 (A) Axial T2-weighted image showing hyperintensity involving the basis pontis, crossing the midline and sparing the periphery. (B) Axial fluid-attenuated inversion recovery image showing non-suppression of the T2 hyperintense lesion. (C) Axial T1-weighted image showing corresponding hypointensity in the basis pontis. (D) Diffusion-weighted image showing restricted diffusion (apparent diffusion coefficient (ADC) map not available). quadriparetic with muscular strength of $0 / 5$ involving all four limbs, with brisk reflexes and an extensor plantar reflex, consistent with a locked-in state (video 1). His condition was static for 3 days. As we found evidence of use of intravenous immunoglobulin in osmotic demyelination syndrome in the literature, it was started for this patient at $0.4 \mathrm{~g} / \mathrm{kg}$ body weight/day for 5 days. ${ }^{1}$ Over a period of 3 days, he started moving his lower limbs and by the sixth day he had started moving his upper limbs. An elective tracheostomy was performed on day 7. On the eighth day, his lower limb muscular strength improved to $3 / 5$ and upper limb muscular strength was $2 / 5$. He was weaned from the ventilator on day 14 . Fifteen days after intravenous immunoglobulin, he was able to sit up, and by the third week he was able to walk with support (video 2).

Osmotic demyelination syndrome is a clinical entity usually occurring due to rapid correction of hyponatraemia. ${ }^{2} 3$ Alcoholism and malnutrition are other common causes. In this patient, alcohol was presumed to be the causative factor as his serum electrolytes were normal and he had a positive history of alcoholism (his alcohol consumption was half a litre of whisky per day for a period of 3 months).

Osmotic demyelination syndrome characteristically involves the pons, with extrapontine structures such as the basal ganglia being affected occasionally. In the pons, the basis pontis is predominantly involved and the tegmentum is spared giving rise to the typical MRI appearance. There is greatest admixture of grey and white matter at the basis pontis and this has been postulated as the reason for its involvement in osmotic demyelination

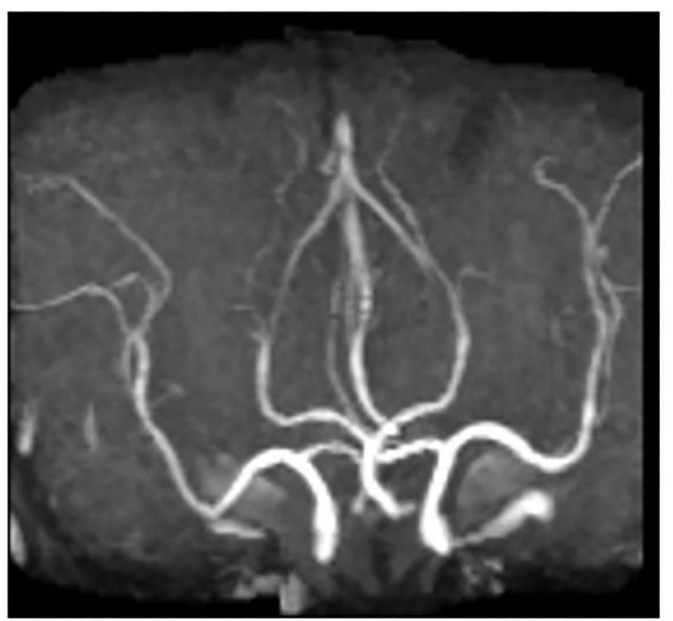

Figure 2 MR angiogram of the patient is normal. 


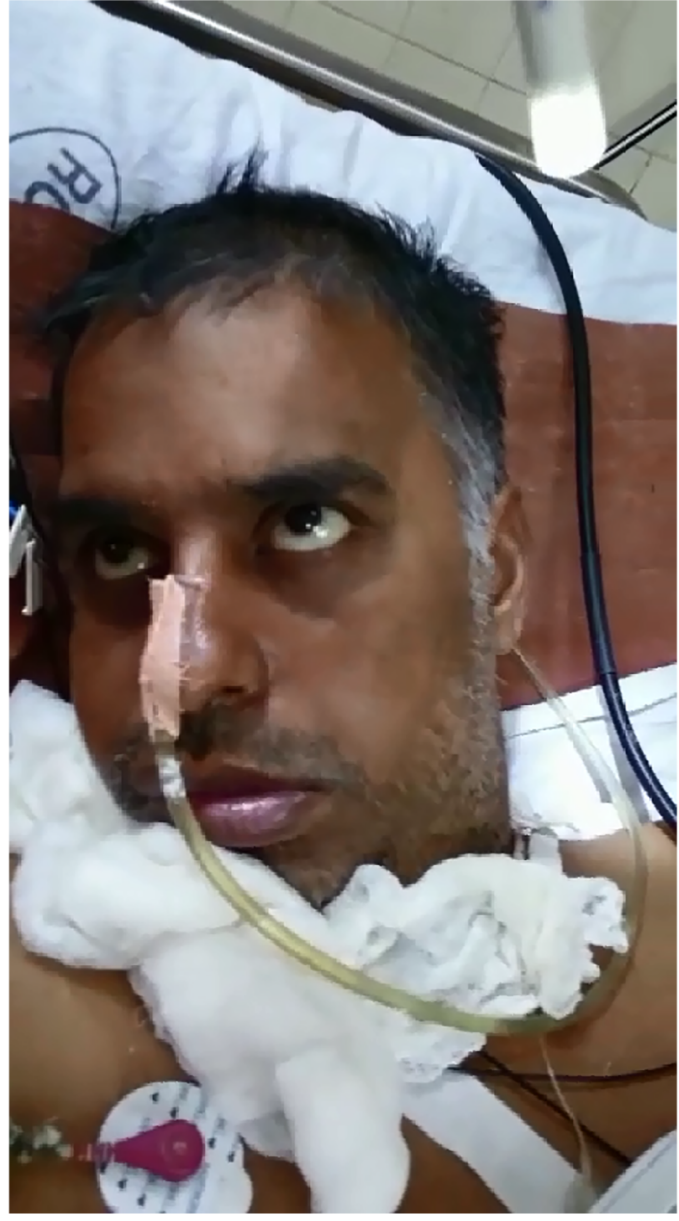

Video 1 The patient is quadriplegic with bifacial palsy with preserved sensorium and eye movements consistent with a 'locked-in state'.

syndrome. ${ }^{1}{ }^{2}$ It is also termed as myelinolysis because the pathology is osmotic demyelination characterised by intramyelinitic splitting, vacuolisation and myelin sheath rupture. ${ }^{4}$ This clinical

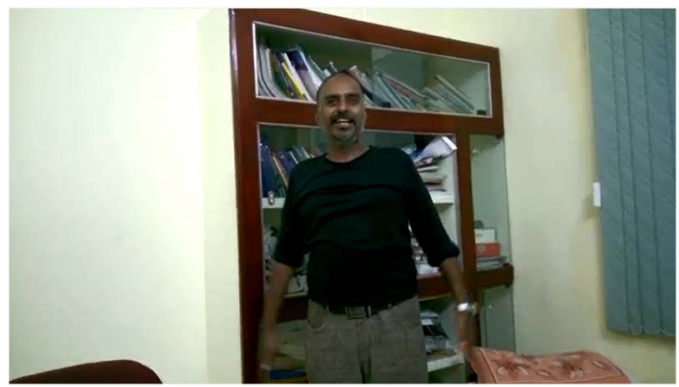

Video 2 Three weeks after the onset of intravenous immunoglobulin, the patient is ambulatory. condition has a variable prognosis and has no treatment. Our patient had deteriorated initially and progressed to a locked-in state. After starting on intravenous immunoglobulin, he made a rapid clinical recovery and became ambulant. Promotion of remyelination and reduction of myelinotoxic antibodies are the putative mechanisms for efficacy of intravenous immunoglobulin. The lack of specific treatment for osmotic demyelination syndrome and the favourable response to intravenous immunoglobulin in cases reported in the literature prompted us to try it for this devastating illness. ${ }^{1}$

\section{Learning points}

- Osmotic demyelination syndrome is a clinical entity that usually occurs secondary to rapid correction of hyponatraemia. However, it can also occur in alcoholic patients with malnutrition.

- Oligodendroglial demyelination and apoptosis appear to be implicated in the pathogenesis that occurs due to metabolic/ osmotic stress. Another postulation is accumulation of myelinotoxic antibodies due to an astroglial reaction.

- MRI is the investigation of choice for diagnosing osmotic demyelination syndrome. The characteristic involvement of basis pontis reflecting as $\mathrm{T} 1$ hypointensity and $\mathrm{T} 2$ hyperintensity not suppressed on fluid-attenuated inversion recovery, and the presence of diffusion restriction, usually clinches the diagnosis. Associated sparing of the periphery gives the typical 'trident sign', or 'Mexican hat sign'.

- Immunoglobulins as a treatment modality in osmotic demyelination syndrome must be considered for this devastating condition as immune mechanisms described earlier are postulated in the pathogenesis of this clinical entity.

Contributors ST and AG were the clinicians in charge of the patient. ST drafted the manuscript. $A B$ and FF participated in the diagnosis of the patient, as well as editing and proof reading the manuscript. All the authors reviewed the manuscript prior to submission.

Competing interests None declared.

Patient consent Obtained.

Provenance and peer review Not commissioned; externally peer reviewed.

\section{REFERENCES}

1 Finsterer J, Engelmayer $\mathrm{E}$, Trnka $\mathrm{E}$, et al. Immunoglobulins are effective in pontine myelinolysis. Clin Neuropharmacol 2000;23:110-13.

2 Martin R. Central pontine and extrapontine myelinolysis: the osmotic demyelination syndromes. J Neurol Neurosurg Psychiatry 2004;75(Suppl 3):iii22-8.

3 Graff-Radford J, Fugate JE, Kaufmann TJ, et al. Clinical and radiologic correlations of central pontine myelinolysis syndrome. Mayo Clin Proc 2011;86:1063-7.

4 Ruzek KA, Campeau NG, Miller GM. Early diagnosis of central pontine myelinolysis with diffusion-weighted imaging. Am J Neuroradiol 2004;25:210-13. 
Copyright 2015 BMJ Publishing Group. All rights reserved. For permission to reuse any of this content visit http://group.bmj.com/group/rights-licensing/permissions.

BMJ Case Report Fellows may re-use this article for personal use and teaching without any further permission.

Become a Fellow of BMJ Case Reports today and you can:

- Submit as many cases as you like

- Enjoy fast sympathetic peer review and rapid publication of accepted articles

- Access all the published articles

- Re-use any of the published material for personal use and teaching without further permission

For information on Institutional Fellowships contact consortiasales@bmjgroup.com

Visit casereports.bmj.com for more articles like this and to become a Fellow 